\title{
Performance in the US telecommunication services industry
}

\section{An analysis of the impact of deregulation}

\author{
Sumit K. Majumdar
}

The Impact of deregulation on the performance of firms in the US telecommunication services industry is exemined, using extant ldeas to suggest that deregulation has differing impacts on different dimensions of firms' performance. The performance of the top 39 local exchange companles is measured over the period 1981-87 using a multiporlod, multi-output ratio analysis model which enables disaggregation of gross performance measures into several detalled components. The findinge Indicate that deregulation has a sinnificant impact on different dimensions of firms' performance in general, and it is also found that individual firms cleplay different patterns of response in each of these dimensions of perform. ance.

The author is Assistant Professor of Corporate Strategy, School of Business Administration, The University of Michigan, Ann Arbor, MI 48109, USA (Tel: 313763 4610).

'Good histories of the events that have
taken place are found in Gerald Brock, The
Telecommunications Industry: The Dyna-
mics of Market Structure, Harvard Uni-
versity Press, Cambridge, MA, 1981; and
in Gerald R. Faulhaber, Telecommunica-
tions in Turmoil: Technololgy and Public
Policy, Ballinger, Cambridge, MA, 1987 .
2The underlying methodological basis for
these ratios is documented and described
continued on page 328
In the US telecommunications industry a major restructuring has taken place in the last decade, with industry boundaries blurring and increasing pressures on regulatory commissions, leading to the intensification of competition in what was once the Bell monopoly market. ${ }^{1}$ Given such dynamic events, the principal question addressed in this article is: has the performance of firms providing telecommunication services in the USA changed as a result of deregulation? Analysing firms' performance within contexts of contemporary importance is of major interest to management and public policy makers, and the impact of deregulation in US telecommunications provides an apposite context for study.

In carrying out the study, a new multi-period, multi-product performance measurement model is used. Traditional performance measures in business include the return on investment (ROI) formula, while economic performance is measured by productivity indices. The method used integrates the ROI formula with productivity measurement frameworks to come up with a set of five ratios which yield rich insights into the performance of US telecommunications firms as their regulated environment unravels. ${ }^{2}$ By analysing the time paths of these ratios, and differences in the ratios between firms with respect to industry averages, the responses of individual firms to the changing environment are gauged.

\section{General impact of deregulation}

Deregulation is a liberalization measure going to the heart of attempts to improve the economic performance of industries, and a key question is: why are there differences in the performance of firms in a regulated versus deregulated environment, particularly where the same collection of employees who managed the old regulated firms are in charge in the 
continued from page 327

in Rajiv Banker, Srikant M. Datar and Robert S. Kaplan, 'Productivity measurement and management accounting', Journal of Accounting, Auditing and Finance, Fall 1989, pp 528-544; and in Rajiv Banker, Hsi-Hui Chang and Sumit K. Majumdar. 'Analyzing the underlying dimensions of firm profitability', Managerial and Decision Economics, forthcoming.

${ }^{3}$ J.A. Kay and D.J. Thompson, 'Privatization: a policy in search of a rationale', Economic Journal, March 1986, pp 18-32. ${ }^{4}$ William S. Comanor and Harvey Leibenstein, 'Allocative efficiency, X-efficiency and the measurement of welfare losses', Economica, August 1969, pp 304-309; Oliver D. Hart, 'The market mechanism as an incentive scheme', Bell Journal of Economics, Vol 14, 1983, pp 366-382; John Vickers and George Yarrow, Privatization: An Economic Analysis, MIT Press, Cambridge, MA, 1988.

${ }^{5} \mathrm{~A}$. Michael Spence, 'Cost reduction, competition and industry performance', in Joseph E. Stiglitz and G. Frank Mathewson, eds, New Developments in the Analysis of Market Structure, MIT Press, Cambridge, MA, 1986.

${ }^{6}$ Carson Agnew and Anthony Romeo, 'Restructuring the US telecommunications industry: impact on innovation', Telecommunications Policy, Vol 5, No 4, December 1981, pp 273-288.

${ }^{7}$ Alfred E. Kahn, The Economics of Regulation: Principles and Institutions, MIT Press, Cambridge, MA, 1988.

${ }^{8}$ William J. Baumol and Alvin Klevorick, 'Input choice and rate of return regulation: an overview of the discussion', Bell Journal of Economics and Management Science, Vol 1, Autumn 1970, pp 162-190; John F. Mahon and Edwin A. Murray, 'Regulation and strategic transformation', Journal of Contemporary Business, Vol 9, No 2 , 1980, pp 123-138.

${ }^{9}$ Harvey Averch and Leland Johnson, 'Behaviour of the firm under regulatory constraint', American Economic Review, Vol 52, 1962, pp 1052-1069; Leon Courville 'Regulation and efficiency in the electric utility industry', Bell Journal of Economics and Management Science, Vol 5, Spring 1974, pp 53-74; Walter Primeaux, 'The impact of competition on capacity utilization in the electric utility industry', Economic Inquiry, Vol 16, April 1978, pp 237248

${ }^{10}$ R.E. Miles and C.C. Snow, Organizational Strategy, Structure and Process, McGraw-Hill, New York, NY, 1978; Richard R. Nelson and Sydney G. Winter, An Evolutionary Theory of Economic Change, Harvard University Press, Cambridge, MA, 1982; E.F. Penrose, The Theory of the Growth of the Firm, with a new introduction by Martin Slater, St Martins Press, New York, NY, 1980.

${ }^{11} \mathrm{John}$ Langdale, 'Competition in telecommunications', Telecommunications Policy, Vol 6, No 4, December 1982, pp 283-299; continued on page 329 new regime $?^{3}$ Deregulation enhances the competitive environment of firms, spurring them to become internally efficient and better their overall performance. ${ }^{4}$ Because the environment of a firm establishes the context within which operations are carried out and performance outcomes attained, performance changes after deregulation are brought about not because of a sudden change in the abilities of incumbent management, but because of the changing constraints and opportunities faced in a more competitive environment.

A firm's ROI can be affected by many factors such as its overall profitability, productivity and ability to recover high prices, its focus on courses of action yielding greater returns and the proper utilization of plant capacity. Deregulation changes a firm's environment and affects all of these. Profitability often rises in the early post-deregulation period for existing firms since market opportunities are greater. But, as more firms enter the market, concentration within the market is reduced and price-cost or profitability margins drop. ${ }^{5}$ Productivity increases because of competitive pressures and, though incentives to innovate are higher, ${ }^{6}$ competition drives prices down to marginal costs. ${ }^{7}$ Emerging market opportunities also enable shifting corporate focus to profitable areas, because in a deregulated environment rate structures keeping inefficient firms in business no longer exist, while the possibilities of earning returns from notable entrepreneurial achievements are no longer precluded ${ }^{8}$ and parsimony in the use of assets leads to a better utilization of plant capacity and other physical resources. ${ }^{9}$

Thus deregulation has differential impacts on different aspects of a firm's performance. Nonetheless, among firms there can be further performance differences because of unique firm-level predilections, different sets of administrative competencies or idiosyncratic response routines. Hence among firms different dimensions of performance can significantly differ. ${ }^{10}$

\section{The context}

Performance measures are formulated for the local operating companies in the USA for three time periods: 1981, 1984 and 1987. These companies have a mix of regulated and unregulated business, with the unregulated proportion steadily increasing. The primary regulated business is the provision of local household services. Provision of local business services is also partially regulated, but market entry is possible in areas such as private line and value-added sevices. Revenues from big business customers account for a substantial part of revenues of the companies, and these customers are free to choose from a host of alternative suppliers. Thus among the local companies the extent of competitive pressure is keenly felt. ${ }^{11}$

Local operating companies also provide long-distance services within their jurisdictional areas, called Local Access and Transport Areas (LATA). While for some of these companies intra-LATA long-distance services are regulated, in several key highly populated states such as Florida these services are fully deregulated, and progressive deregulation is occurring elsewhere. Hence for local operating companies the competitive pressures faced have exacerbated over time. The period 1981-84 can be considered to be one of political transition, with 1981 an appropriate stating point for the study. 1981 was a period of full regulation and 1984 a year of partial regulation. By 1987 deregulation 
had increased, and the phase between 1984 and 1987 is therefore one of increasing competition.

\section{Performance analysis measures}

Traditionally the ROI formula has been decomposed into its component parts as follows:

$$
\begin{aligned}
\mathrm{ROI} & =\text { profit/assets } \\
& =(\text { profit/revenues }) \times(\text { revenues/assets }) \\
& =\left(1-\pi^{-1}\right) \times(\text { revenues/assets })
\end{aligned}
$$

where $\pi^{-1}$ is the reciprocal of the profitability margin computed as revenues divided by costs. The profitability margin for a firm can be defined for some period $t$ generally as:

$$
\pi^{t}=\sum_{m} P_{m}^{t} y_{m}^{t} /\left(\sum_{v} W_{v}^{t} x_{v}^{t}+\sum_{f} w_{f}^{t} x_{f}^{t}\right)
$$

where:

$y_{m}^{t}=$ actual quantities of outputs in during period $t, m=1,2, M$; $t=1,2, T$

$P_{m}^{t}=$ price per unit of output during period $t$

$x_{v}^{t}=$ actual quantity of variable cost input $v, v=1,2, V$, during period $t$

$w_{v}^{t}=$ price per unit of variable cost $v$ during period $t$

$x_{f}^{t}=$ actual quantity of fixed cost input $f, f=1,2, F$, during period $t$

$w_{f}^{t}=$ price per unit of fixed cost input $f$ during period $t$

To analyse performance over time the profitability change ratio can be defined as a ratio of ratios, the ratio of the profit margin ratio for period $t$ to the profit margin ratio for some base level 0 :

$$
\text { PFTBLT }=\frac{\Pi^{t}}{\Pi^{\circ}}
$$

The profitability change ratio can then be decomposed into four ratios which when multiplied together equal the profitability change ratio. The four ratios so developed are as follows. Details of how to calculate them are given in Appendix 1.

Productivity change ratio. The ratio compares actual usage of inputs to the standard inputs required, which are calculated based on average input requirements for the industry data set as a whole given the actual outputs and output capacities of a firm for each time period.

Price recovery change ratio. This ratio shows how effective the firm is in maximizing output prices while minimizing input prices, and thereby measures the price efficiency of firms. The ratio compares the value of outputs and inputs at base level prices, while holding both outputs and inputs constant at base levels.

continued from page 328

John R. Meyer, R.W. Wilson, M. Alan Baughcum, E. Burton and L. Caouette, The Economics of Competition in the Telecommunications Industry, Oelgeschlager, Gunn \& Hain, Cambridge, MA, 1980.
Product mix change ratio. This ratio shows what impact changing the product mix or the service mix of a firm has on its profitability over time.

Capacity utilization change ratio. The capacity utilization change ratio measures efficiency of physical capital in a firm. There is a fixed stock of 
these, and hence a standard output is expected based on technical considerations. To the extent that such capacity utilization improves, a greater than standard level of output from such physical capital is expected and it can be inferred that assets already in place are being used to generate greater amounts of output.

Performance measures are calculated for 39 major local telephone operating companies in the USA with 1987 annual revenues of $\$ 100$ million or more.

To calculate the performance ratios certain basic data about a firm's operation are required. These include details of its outputs, the composition of its revenues streams, how the total operating expenses are composed, and details about the physical assets or resources that enable it to provide the products or services that it does. The following measures are used to compute ratios of performance.

Two physical output measures are chosen. They are the annual total minutes of local and toll calls respectively. Financial output measures are local and toll call revenues. Toll revenues also include access revenues earned by the companies because they permit their networks to be used by other long-distance companies, and miscellaneous revenues are split between local and toll revenues in the proportion that each bears to total operating revenues.

The physical resources of these firms are their total access lines in place, and these signify their ability to service customers. Allied to the measures of output and physical capacity are the operating costs incurred. Maintenance and depreciation costs are categorized as fixed costs, which are based on plant capacity, while traffic, commercial, general office and other expenses are costs which vary with the volume of activity.

\section{Overall analysis of performance}

Figure 1 shows how the performance ratios for the industry as a whole have behaved from 1981 and 1987 . It is found that profitability rises in 1984 relative to 1981 following deregulation, and then falls in 1987 relative to 1984 . The productivity change ratio rises both in 1984 relative to 1981 , and in 1987 relative to 1984 . The price recovery change ratio falls consistently, in 1984 relative to 1981 and in 1987 relative to 1984 . The product mix change ratio on the other hand rises in 1984 relative to 1981 , and keeps rising in 1987 relative to 1984 , while the capacity utilization ratio rises dramatically from 1981 to 1984, but declines somewhat between 1984 and 1987 . The results of the statistical tests carried out on the ratios are given in Table 1.

\section{Behaviour of the profitability change ratio}

From Table 1 it is noted that the mean of the 1984 ratio is greater than that for 1981, suggesting that profitability margins do increase significantly after deregulation and divestiture. The 1987 mean of the ratio is also greater than that for 1981 . However, it is also found that the 1987 mean of the ratio is significantly lower than that for 1984 .

\section{Behaviour of the productivity change ratio}

Productivity is a key component that contributes to a firm's profitability. Reviewing Figure 1 it can be seen that the productivity ratio increases 
Figure 1. Average performance of all firms.
Note: A comparison of each ratio was carried out between pairs of years using the test outlined in B.L. Welch, "The significance of the difference between two means when the population variances are unequal', Biometrika, 1937, pp 350-362.

All these year-wise comparisons are statistically significant using Welch's test, at least at $p<$

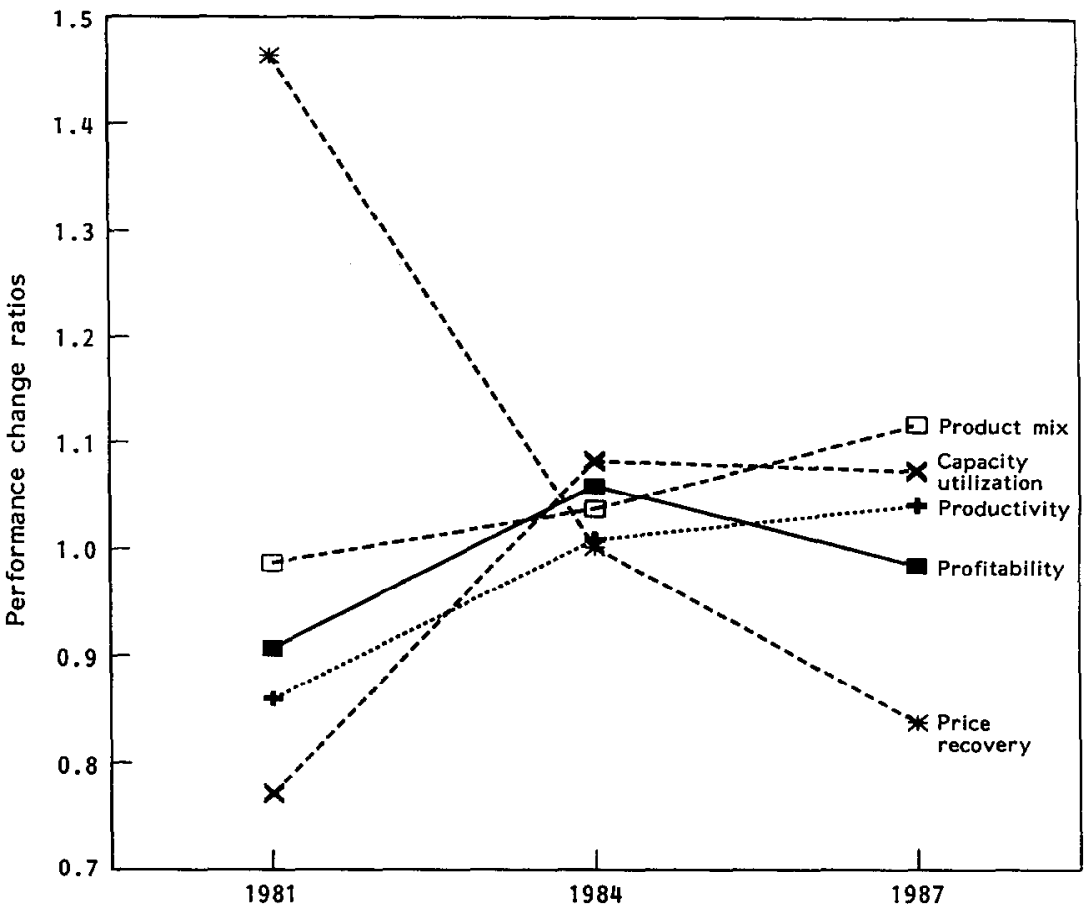

consistently from 1981 to 1984 , and from 1984 to 1987 . The increase from 1981 to 1984 is statistically significant for the mean of the ratio, while the 1987 mean is significantly greater than that for 1984 . The fact that the productivity ratio increases monotonically over the entire period 1981-87 is also supported by the fact that the 1987 mean is greater than that for 1981.

\section{Behaviour of the price recovery change ratio}

In Figure 1 it is noted that the price recovery change sharply declines from 1981 to 1984 , and further declines from 1984 to 1987, though not as sharply. This suggests that competition from new entrants brings extremely strong pressures on the erstwhile monopoly telecommunications firms to reduce their prices.

From Table 1 it is also noted that the decrease in the price recovery ratio is monotonically significant throughout the period of our study. The mean of the ratio is lower for 1984 than in 1981, the mean of the ratio for 1987 is lower for 1987 than in 1984 , and the 1987 mean is lower for 1987 than 1981.

Table 1. Test of whether the means of the ratios calculated for the operating companles are monotonlcally increasing.

\begin{tabular}{|c|c|c|c|}
\hline . & $\begin{array}{l}\text { Is the } 1984 \text { moan } \\
\text { ratio greeter than } \\
\text { the } 1981 \text { mean ratio? }\end{array}$ & $\begin{array}{l}\text { Is the } 1987 \text { mean } \\
\text { retio greater than } \\
\text { the } 1984 \text { mean ratio? }\end{array}$ & $\begin{array}{l}\text { Is the } 1987 \text { mean } \\
\text { ratio greater than } \\
\text { the } 1981 \text { mean ratio? }\end{array}$ \\
\hline \multirow{5}{*}{$\begin{array}{l}\text { Profitability change } \\
\text { ratio } \\
\text { Productivity change } \\
\text { ratio } \\
\text { Price recovery change } \\
\text { ratio } \\
\text { Product mix change } \\
\text { ratio } \\
\text { Capacity utilization } \\
\text { ratio }\end{array}$} & $Y_{e s}^{a}$ & No & $Y_{e s}{ }^{a}$ \\
\hline & Yes" & Yes & Yes \\
\hline & $\mathrm{No}^{\mathrm{a}}$ & $\mathrm{No}^{a}$ & $\mathrm{No}^{a}$ \\
\hline & $Y_{e s}^{a}$ & Yes & Yes ${ }^{a}$ \\
\hline & Yes ${ }^{a}$ & No & Yes $^{a}$ \\
\hline
\end{tabular}




\begin{tabular}{|c|c|c|c|}
\hline & $\begin{array}{l}\text { Behaviour of ratios } \\
1981-84\end{array}$ & $\begin{array}{l}\text { Behaviour of ratios } \\
\text { 1984-87 }\end{array}$ & $\begin{array}{l}\text { Behaviour of ratios } \\
1981-87\end{array}$ \\
\hline $\begin{array}{l}\text { Central Telephone } \\
\text { Profitability change } \\
\text { Productivity change } \\
\text { Price recovery change } \\
\text { Product mix change } \\
\text { Capacity utilization change }\end{array}$ & $\begin{array}{l}\text { Rise } \\
\text { Rapid rise } \\
\text { Rapid decline } \\
\text { Rise } \\
\text { Rapid rise }\end{array}$ & $\begin{array}{l}\text { Decline } \\
\text { Rapid rise } \\
\text { Rapid decline } \\
\text { Rise } \\
\text { Rise }\end{array}$ & $\begin{array}{l}\text { Rise and decline } \\
\text { Rise } \\
\text { Decline } \\
\text { Rise } \\
\text { Rise }\end{array}$ \\
\hline $\begin{array}{l}\text { Cincinnati Bell } \\
\text { Profitability change } \\
\text { Productivity change } \\
\text { Price recovery change } \\
\text { Product mix change } \\
\text { Capacity utilization change }\end{array}$ & $\begin{array}{l}\text { Rapid rise } \\
\text { Rise } \\
\text { Rapid decline } \\
\text { Rise } \\
\text { Rapid rise }\end{array}$ & $\begin{array}{l}\text { Rise } \\
\text { Rise } \\
\text { Decline } \\
\text { Rise } \\
\text { Decline }\end{array}$ & $\begin{array}{l}\text { Rise } \\
\text { Rise } \\
\text { Decline } \\
\text { Rise } \\
\text { Rise and decline }\end{array}$ \\
\hline $\begin{array}{l}\text { GTE Southwest } \\
\text { Profitability change } \\
\text { Productivity change } \\
\text { Price recovery change } \\
\text { Product mix change } \\
\text { Capacity utilization change }\end{array}$ & $\begin{array}{l}\text { Rapid rise } \\
\text { Rapid rise } \\
\text { Rapid decline } \\
\text { Rise } \\
\text { Rapid rise }\end{array}$ & $\begin{array}{l}\text { Rapid decline } \\
\text { Rapid decline } \\
\text { Rapid rise } \\
\text { Rise } \\
\text { Rapid decline }\end{array}$ & $\begin{array}{l}\text { Rise and decline } \\
\text { Rise and decline } \\
\text { Decline and rise } \\
\text { Rise } \\
\text { Rise and decline }\end{array}$ \\
\hline $\begin{array}{l}\text { Pacific Telephone } \\
\text { Profitability change } \\
\text { Productivity change } \\
\text { Price recovery change } \\
\text { Product mix change } \\
\text { Capacity utilization change }\end{array}$ & $\begin{array}{l}\text { Rapid rise } \\
\text { Rapid rise } \\
\text { Rapld decline } \\
\text { Rise } \\
\text { Rapid rise }\end{array}$ & $\begin{array}{l}\text { No change } \\
\text { Rapid rise } \\
\text { Decline } \\
\text { Rise } \\
\text { Decline }\end{array}$ & $\begin{array}{l}\text { Rise } \\
\text { Rise } \\
\text { Decline } \\
\text { Rise } \\
\text { Rise and decline }\end{array}$ \\
\hline
\end{tabular}

\section{Behaviour of the product mix change ratio}

Table 1 shows that the product mix change ratio also increases monotonically over the periods we study. The 1987 mean is greater than the 1981 mean, the 1987 mean is greater than the one for 1984 , and the 1984 mean is greater than the one for 1981.

\section{Behaviour of the capacity utilization change ratio}

A rapid increase in capacity utilization is also found between 1981 and 1984 and in the overall period between 1981 and 1987. However, between 1984 and 1987 there is a drop in this ratio which is not statistically significant.

The implications of such a drop are twofold. One is that, after the initial post-deregulation slack has been squeezed out, firms are content to keep a level of capacity that will enable them to provide other products or services as markets open. The second is that after deregulation firms have adjusted their scale of operations to one which is most productive, and future improvements in the capacity utilization ratio will only occur because of major technical change.

\footnotetext{
${ }^{12}$ These comments are based on an extensive analysis of US operating companies that is contained in Leonard Hyman, Richard Toole and Rosemary Avellis, The New Telecommunications Industry: Evolution and Organization, Public Utilities Reports, 1987.
}

\section{Analysis of specific performance}

The approach taken so far has been to evaluate the influences that deregulation generally has on firms. Nevertheless it is recognized that there will be specific differences in how each of the performance measures behaves over time for each firm. Four firms are commented on: Central Telephone, Cincinnati Bell, GTE Southwest and Pacific Telephone. ${ }^{12}$ Table 2 summarizes how the various ratios for each sample firm behave over time. It is a tabular snapshot of Figures 2-5, which show the individual ratios and their movements contributing to the overall performance of each firm.

Central Telephone is the 'flagship' of the Centel group, and operates 
Figure 2. Performance of Central Telephone.

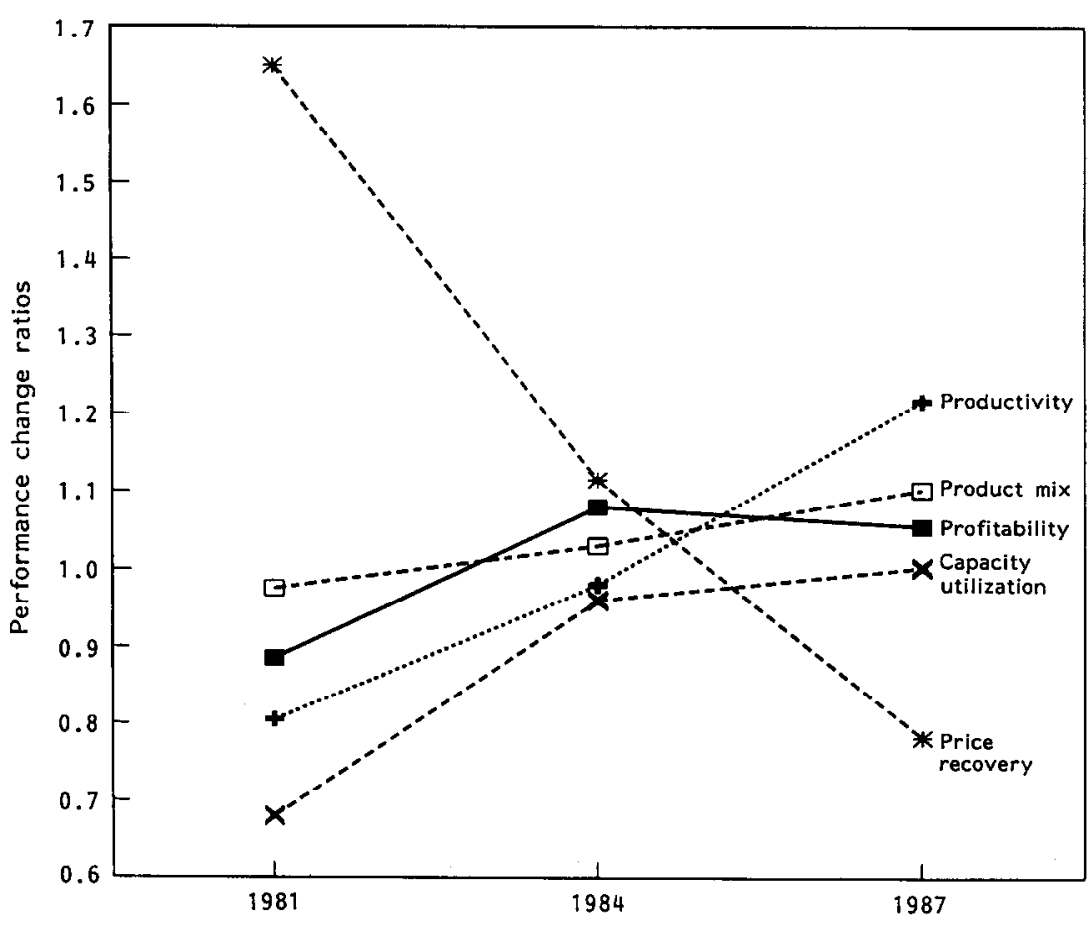

in four Midwestern states. Its performance is shown in Figure 2. In common with almost all other firms it shows an increase in profitability from 1981 to 1984 . The main contribution to this overall increase comes from the increase in its productivity and capacity utilization, though its attention to a profitable product mix also helps, and these negate the effect of the decline in price recovery. In the period 1984-87 its profitability margin declines, primarily due to a decline in price recovery. Nonetheless its productivity and capacity utilization ratios increase as a result of aggressive spending on new technology, and Central Telephone seems to be following an efficiency-oriented, low-cost approach to its market.

In Figure 3 the performance of Cincinnati Bell can be viewed. It is an independent telephone company, serving a major urban market in the Midwest where the scope for competition is high. It is a firm in which the profitability margin increases both from 1981 to 1984 and from 1984 to 1987 . Its price recovery ratio for 1981 is not as high as that of Central Telephone, suggesting that its market is already competitive. Nevertheless this ratio declines from 1981 to 1984 and from 1984 to 1987 . To counteract this, there is a monotonic increase in both the productivity and product mix ratios, and an early increase in capacity utilization. However, it is visually apparent that it is the product mix ratio which rises more steeply. This suggests that attention to a differentiated product range with higher margins is Cincinnati Bell's approach in the post-deregulation period, and quite feasibly so given the high business orientation in its operating area.

GTE Southwest displays idiosyncratic performance over the periods studied, as shown in Figure 4. In our sample it is the only firm whose profitability margin declines very sharply in the period 1984-87, to almost 1981 levels. It is the only firm whose productivity and capacity utilization ratios, while rising after 1981 , decline sharply from 1984 to 1987. On the other hand, it is the only firm whose price recovery ratio 
Figure 3. Performance of Cincinnati Bell.

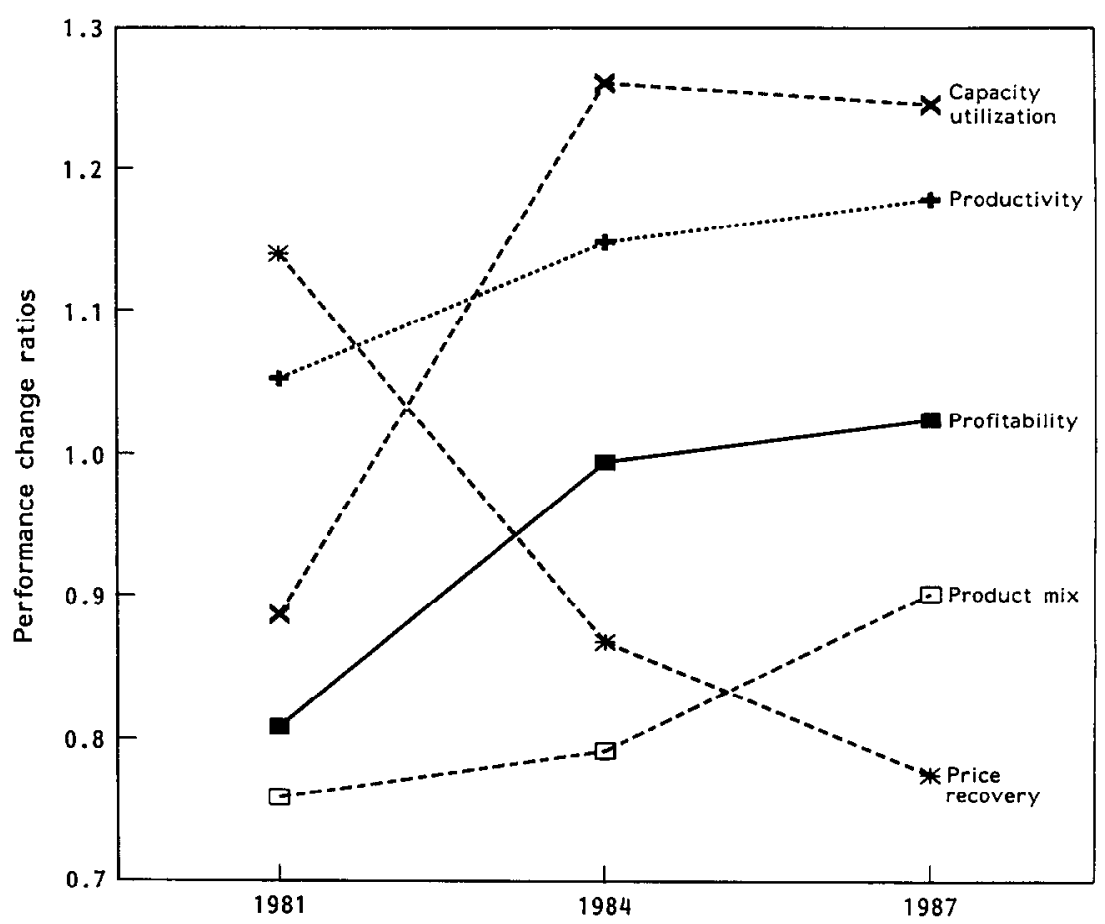

rises after 1984. These, coupled with the fact that the product mix ratio also rises steadily throughout, suggests that GTE Southwest is attempting an externally oriented approach directed towards managing its political relations with the regulatory authorities so as to attain higher than average prices. It does not seem to have fully effective internal operating mechanisms which would contribute to increased productivity and capacity utilization. The result is that overall profitability falls sharply as the environment become more competitive.

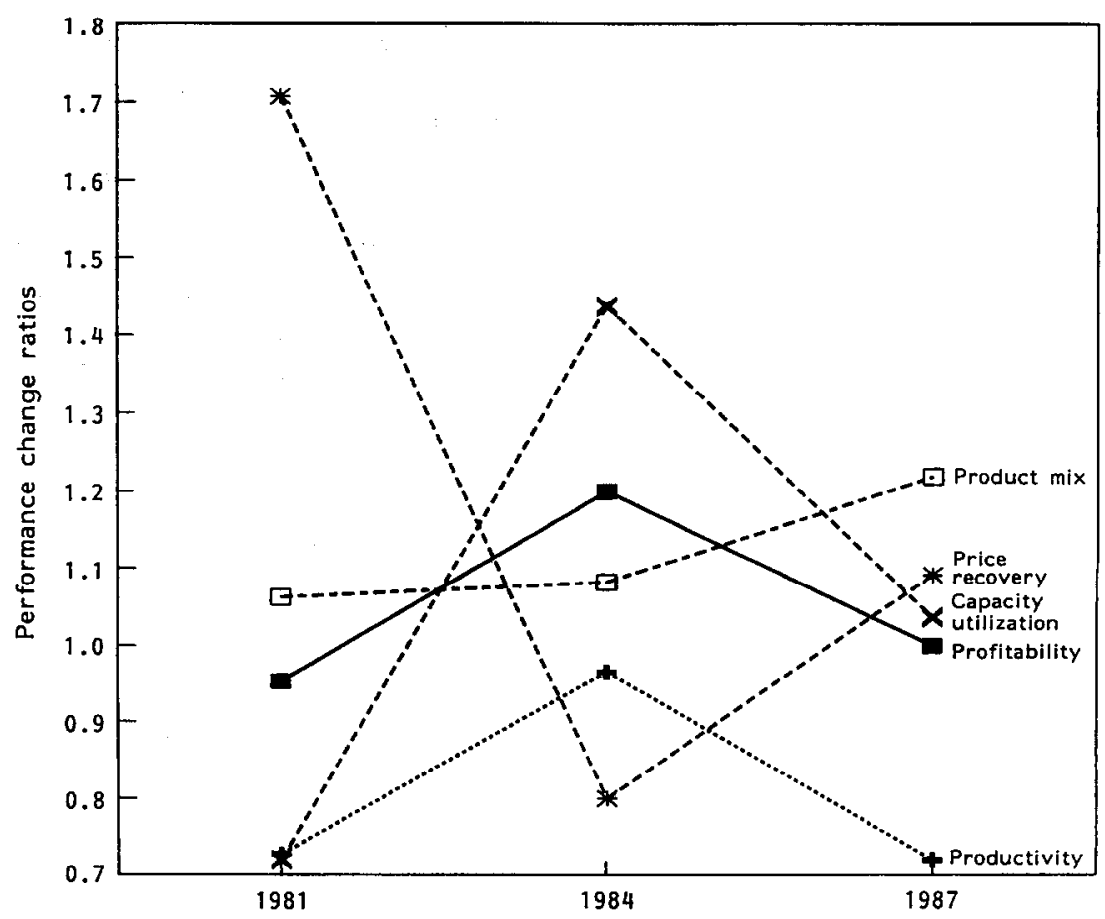

Figure 4. Performance of GTE Southwest. 
Figure 5. Performance of Pacific Telephone.

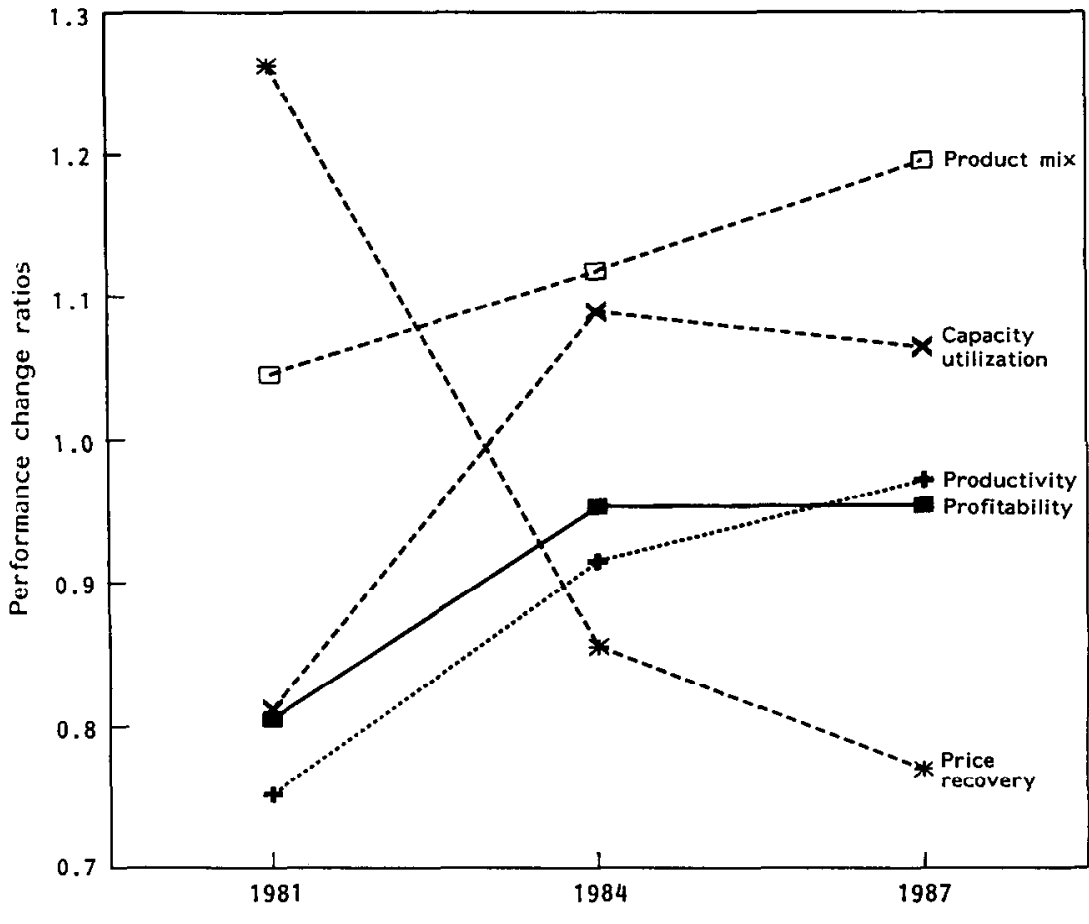

The performance of the fourth company in the sample, Pacific Telephone, is displayed in Figure 5. Pacific Telephone operates in the very competitive Californian market with several other big players. Historically it was given stepmotherly treatment by AT\&T. However, with deregulation in 1984 major changes took place in both its strategic and operational postures. From Figure 5 it is apparent that while profitability margins do rise sharply from 1981 to 1984 , they stay at the same level for the period 1984-87. A reason for this is the continuous drop in the price recovery ratio, not unexpected in the Californian environment. Yet two ratios which displayed strong monotonic rises from 1981 to 1984 and from 1984 to 1987 are the productivity ratio and the product mix ratio. This suggests that the company is being aggressive in both cutting costs and focusing on market-driven strategies. What is also spectacular is the sharp rise in capacity utilization from 1981 to 1984 , and these three factors combine effectively to counter the sharp drop in price recovery, thus leading to higher profit margins.

\section{Conclusions}

It is demonstrated that the impact of deregulation has significantly affected the performance of firms in the US telecommunications industry. This validates several assumptions, in both the management and public policy literature, that deregulation will have positive impacts on the performance of firms.

Also demonstrated is the fact that while overall profitability margins may rise and then fall, separate components of firms' performance that contribute to profitability all change significantly, either positively or negatively. With increasing competition we expect the price recovery ability of firms to drop as more service suppliers seek revenues from existing customers. However, to counteract such trends firms increase 
their operational efficiencies through incrcasing productivity and capacity utilization, and by paying attention to products with a higher margin.

While the above comments refer to the overall industry analysis, it is also seen that individual firms' performance also differs on various dimensions. This is the case in the, albeit limited, sample of four firms. All reflect unique and divergent trends in responding to the challenges of a deregulated environment. Within a homogeneous industry heterogeneous firm-level differences in performance, as a result of the same environmental change, are identified. It is reiterated, however, that specific intrafirm actions that might lead to such differences are not identified, though suggestions as to what these might be are made. Extensions to the study are thus warranted.

A subsequent approach will be to take the performance ratios and use them as dependent variables in econometric models, using specific exogenous or endogenous factors as independent explanators. Such tests will not only extend the performance analysis by factoring in the influence of independent variables on the ratios, but will also point to the influence of both firm-specific and industry-level factors on performance, and extend the generalizability of the study.

\section{Appendix}

\section{Calculating the performance ratios}

The productivity change ratio is defined as the ratio of the productivity ratio for the period $t$ to the base level productivity ratio. It is expressed as:

$$
\text { PRDTVT }=\frac{\left(\Sigma_{v} w_{v}^{t} z_{t}^{v}+\sum_{f} w_{f}^{t} z_{f}^{t}\right) \div\left(\Sigma_{v} w_{v}^{t} x_{t}^{v}+\sum_{f} w_{f}^{t} x_{f}^{t}\right)}{\left(\Sigma_{v} w_{v}^{0} z_{v}^{0}+\Sigma_{f} w_{f}^{0} z_{f}^{0}\right) \div\left(\Sigma_{v} w_{v}^{0} x_{v}^{0}+\Sigma_{f} w_{f}^{0} x_{f}^{0}\right)}
$$

The price recovery change ratio is expressed as:

$$
\text { PRCREC }=\frac{\sum_{m} p_{m}^{t} y_{m}^{t} \div \Sigma_{m} p_{m}^{0} y_{m}^{t}}{\left(\sum_{v} w_{v}^{t} z_{v}^{t}+\sum_{f} w_{f}^{t} z_{f}^{t}\right) \div\left(\Sigma_{v} w_{v}^{0} z_{v}^{t}+\sum_{f} w_{f}^{0} z_{f}^{t}\right)}
$$

The product mix change ratio is expressed as:

$$
\text { PRODMIX }=\frac{\sum_{m} p_{m}^{0} y_{m}^{t} \div \Sigma_{m} p_{m}^{0} y_{m}^{0}}{\left(\Sigma_{v} w_{v}^{0} z_{v}^{t}+\Sigma_{f} w_{f}^{0} q_{f}^{t}\right) \div\left(\Sigma_{v} w_{v}^{0} z_{v}^{0}+\Sigma_{f} w_{f}^{0} q_{f}^{0}\right)}
$$

and the capacity utilization change ratio is expressed as:

$$
\text { CAPUTIL }=\frac{\sum_{v} w_{v}^{0} z_{v}^{t}+\sum_{f} w_{f}^{0} q_{f}^{0}}{\sum_{v} w_{v}^{0} z_{v}^{t}+\sum_{f} w_{f}^{0} z_{f}^{t}}
$$

where $y_{m}^{t}, p_{m}^{t}, x_{v}^{t}, w_{v}^{t}, x_{f}^{t}$ and $w_{f}^{t}$ are as previously defined and

$$
\begin{aligned}
z_{v}^{t}= & \text { standard quantity of variable cost input } v, v=1,2, V, \text { required } \\
& \text { in period } t, t=1,2, T \\
z_{f}^{t}= & \text { standard quantity of fixed cost input } f, f=1,2, F \text { required in } \\
& \text { period } t \\
q_{f}^{t}= & \begin{array}{l}
\text { standard average of fixed cost input } f \text { in period } t \text { given standard } \\
\text { industry capacity utilization. }
\end{array}
\end{aligned}
$$

To calculate the ratios certain assumptions are made. First, the resources available within the firm can generate multiple outputs. Second, substitution possibilities among inputs are not high. Third, production of services may be 
characterized as using fixed proportions of technology, and fourth, input requirements can be approximated linearly within relevant ranges.

The standard quantity $z_{v}^{t}$ of variable cost input $v$ required in any period $t$ is based on the standard input requirement $\alpha_{m v}$ per unit of product $m$. The quantity required is defined as $z_{f}^{t}=\Sigma_{m} \alpha_{m v} y_{m}^{t}$. The standard input requirement $\alpha_{m v}$ is the average industry requirement for an input $v$ to produce or service $m$ and is calculated by regressing pooled inputs, by cost type, on pooled outputs without an intercept term. The two outputs that we use to calculate $\alpha_{m v}$ are local and toll call minutes.

Similarly the standard quantity $z_{f}^{t}$ of fixed cost input $f$ required in period $t$ is based on the standard input requirement $\beta_{f}$ per unit of output capacity available to produce all products. It is defined as $z_{f}^{t}=\beta_{f} k^{t}$, where $k^{t}$ denotes quantities of plant capacity available for outputs during period $t$. The standard input requirement $\beta_{f}$ is based on output capacity available and not on product volume. It is calculated by regressing pooled inputs, by cost type if there are two or more types of fixcd costs, on pooled output capacity available without an intercept.

Having calculated the above, we gain a sense of what standard industryaverage fixed costs are, to produce various outputs, given available physical plant capacity. However, the computation of an average industry fixed cost presupposes average industry capacity utilization given that physical resource capacity is fixed and unique. Hence we need to calculate a standard industry load factor for each period. This is again calculated as an average by dividing the sum of pooled outputs by the sum of pooled plant capacity and is defined as $\left(\Sigma_{m} y_{m}^{0}\right) / k^{0}$. The pooled outputs we use are total local and toll call minutes and the pooled plant capacity is the total number of telephone lines for all firms in all periods. The standard load factor gives us a sense of what average industry capacity utilization in general is and we use it to calculate the standard average quantity of fixed-cost input $f$ in period $t$ based on input requirement $\beta_{f}$, given standard industry capacity utilization. This is defined as $q_{f}^{t}=\beta_{f} \Psi^{0} \sum y_{m}^{t}$, where $\Psi^{0}$ is the inverse of the standard load factor.

We are interested in comparing performance across companies and across time. Hence we also need to calculate common base-level prices and quantities. Using pooled data for all firms in all time periods (in our case we use data for the years 1981, 1984 and 1987), the base output and input prices are calculated as follows:

$$
\begin{aligned}
& p_{m}^{0}=\Sigma_{n} \Sigma_{t} p_{m}^{t} y_{m}^{t} \div \Sigma_{n} \Sigma_{t} y_{m}^{t} \\
& w_{v}^{0}=\Sigma_{n} \Sigma_{t} w_{v}^{t} x_{v}^{t} \div \Sigma_{n} \Sigma_{t} x_{v}^{t} \\
& w_{f}^{0}=\Sigma_{n} \Sigma_{t} w_{f}^{t} x_{f}^{t} \div \Sigma_{n} \Sigma_{t} x_{f}^{t}
\end{aligned}
$$

where $n 1,2, \ldots N$ denotes individual companies and $t=1,2, \ldots T$ denotes the time periods.

Similarly, the base actual output and output capacity quantities are calculated as averages over all firms and all time periods, as follows:

$$
\begin{aligned}
& y_{m}^{0}=\Sigma_{n} \Sigma_{t} y_{m}^{t} \div \mathrm{NT} \\
& k^{0}=\Sigma_{n} \Sigma_{t} k^{t} \div \mathrm{NT}
\end{aligned}
$$

Finally, the base actual and standard input quantities are calculated using estimated input standard $\alpha_{m v}$ and $\beta_{f}$, the estimated standard load factor $\left(\Sigma_{m} y_{m}^{0}\right) / k^{0}$, where $\Psi^{0}=1 /\left(\left[\Sigma_{m} y_{m}^{0}\right] / k^{0}\right)$ and the base output and base capacity details, as follows:

$$
\begin{aligned}
x_{v}^{0} & =z_{v}^{0}=\Sigma_{m} \alpha_{m v} y_{m}^{0} \\
x_{f}^{0} & =z_{f}^{0}=\beta_{f} k^{0} \\
& =q_{f}^{0}=\beta_{f} \Psi^{0} \Sigma_{m} y_{m}^{0}
\end{aligned}
$$

By incorporating technical or other standard input requirements, actual outputs and actual output capacities in the calculation, each component of the productivity ratio (Equation 4) captures only deviations between actual and standard 
usages, and so the productivity change ratio provides a purer measure of productivity change for period $t$. The price recovery change ratio (Equation 5) also incorporates standard input requirements, given current period actual outputs and output capacities. Since $z_{v}^{t}$ and $z_{f}^{t}$ are functions of $y^{t}$, the ratio is driven only by differences in prices.

The product mix change ratio (Equation 6) incorporates the same standard inputs for variable inputs as the other two previous ratios. However, to disentangle the effects of changes in product mix from capacity utilization, for fixed inputs the standard inputs given actual outputs $\left(q_{f}^{t}\right.$ and $\left.q_{f}^{0}\right)$ are incorporated in the denominator ratio. These same standard inputs given actual outputs and the standard load factors for fixed inputs are incorporated in the numerator of capacity utilization change ratio (Equation 7), while the standard inputs for fixed inputs are used in the denominator. However, $q_{f}^{0}=z_{f}^{0}$ in Equation 14, and the capacity utilization change ratio therefore reflects only deviations between $q_{f}^{t}$ and $z_{f}^{t}$ 